\title{
A Comparative Study of Passenger Multitasking Activities on Commuting and Leisure Electrified Intercity Railways
}

\author{
Xing Yao $\left(\mathbb{D}\right.$, Chunhui Jing $\mathbb{D}$, Yaoxuan Huang $\mathbb{D}$, and Jinyi Zhi ${ }^{\mathbb{D}}$ \\ Department of Industrial Design, Southwest Jiaotong University, Chengdu 611756, China \\ Correspondence should be addressed to Xing Yao; yancy216@my.swjtu.edu.cn and Jinyi Zhi; zhijinyi@swjtu.edu.cn
}

Received 15 November 2021; Accepted 24 December 2021; Published 21 January 2022

Academic Editor: Wenxiang Li

Copyright (C) 2022 Xing Yao et al. This is an open access article distributed under the Creative Commons Attribution License, which permits unrestricted use, distribution, and reproduction in any medium, provided the original work is properly cited.

\begin{abstract}
The electrification of intercity railways plays a significant role in energy conservation and emission reduction. Research on passenger travel activities to optimize vehicle services can help to understand how best to improve passenger attraction and the use of intercity railways. In this study, we conducted observational research on two electrified intercity railways that were segregated by the attributes, leisure, and commute. The purpose was to determine the influence of line attribute, passenger gender, age, and seat availability on the types of activities performed onboard, with specific attention placed on the use of information and communication technology (ICT). Using structured observations, the travel multitasking activity data of 467 passengers were collected on two intercity railways in real-life situations. Using the chi-square test and binary logistic regression analysis, it was found that line attribute, gender, age, and seat availability have an impact on passenger activities. Differences in factors affecting passenger activities were also found according to the nature of their travel, whether for commute or leisure. Our results suggest that passengers on the leisure line prefer to engage in some social activities. For example, the probability of conversation among passengers on the leisure line was 3.47 times that of the commuting line, and the middle-aged and elderly travelers on this line were more likely to be in a daze and look around. The probability of taking a break for passengers on the commuting line was 3.625 times that of the leisure line, and passengers who were not seated on this line were found to be more likely to be idle. In addition, male travelers and young travelers preferred to engage in ICT immersive activities, such as using mobile phones, while women, middle-aged, and elderly travelers were more likely to engage in non-ICT immersive activities. Seated passengers were more likely to engage in simultaneous multitasking activities, rest, and conversations than passengers without seats.
\end{abstract}

\section{Introduction}

Local policies [1, 2], actual cases [3], or related technology research [1] have shown that electrification has become an important issue to which academics, local administrative agencies, and the transportation industry officials have all begun paying attention. Electrification transformation in the field of mobile transportation is already one of the productive choices for urban sustainable development. The increase in municipal deployment of environmentally friendly vehicles, such as electric buses, trams, and trolleybuses, can help a city's energy model to shift toward a low-pollution model [4-6]. The railway is one of the four major areas of the transportation industry. Taking China as an example, the rapid development of electrified railways and high-speed trains has contributed to a fluctuating downward trend in carbon dioxide emissions from the railway transportation industry [7]. Furthermore, with the growth of national leisure and entertainment demand, tourism has become the fastest-growing sector in the Chinese economy, and people's demand for railways is rapidly increasing.

It can be seen that the electrification of railways provides a greener and more environmentally friendly means of transportation for urban residents. However, in addition to the existence of sustainable transportation tools, people's willingness to use these tools is another necessary factor for the sustainable development of urban transportation [8]. The European Commission, for example, found that it was necessary to not only upgrade technology to reduce the impact of transportation on the environment but also to increase the attractiveness of trains as a mode of 
transportation. Moreover, with the increasing popularity of information and communication technology (ICT), passenger experience could be enriched with more diverse forms of activities during travel. Collecting evidence about how railway passengers spend their travel time can provide advice to decision-makers, help operators adjust services to better meet passenger needs, and increase the attractiveness of sustainable transportation.

Past experience has shown that the mode of travel was the main determinant of the type of multitasking activity $[9,10]$. Different travel modes lead to differences in the cognitive and physical energy consumption of passengers, which lead to differences in multitasking activities [11]. In the past, comparative studies on multitasking activities between different modes of travel were mostly seen between private and public transportation. Lyons et al. [12] found that passengers had the highest level of productivity on trains, followed by cars and buses. Russell et al. [13] found that there were more people looking ahead/out of the window on the bus than on the train, and more people were reading, using a computer, sleeping, or writing on the train. Singleton et al. [14] found that bus and car passengers engaged in more types of activities, while vehicle (cars and bicycles) drivers engaged in fewer types of activities, most of which were passive activities. Keseru et al. [15] compared the multitasking activities of passengers on buses, trams, and subways and found no significant differences. Utsunomiya [16] surveyed the residents of the two railway areas and found that, compared with the traditional nonelectrified railway areas, the residents of the electrified railway areas were more inclined to shop frequently and participate in local festivals. It can be seen that the existing travel-based multitasking information in the field of public transportation mostly comes from trains, and there are few studies on short- and medium-distance vehicles, such as subways and intercity trains [10], and more detailed comparisons (such as line attribute) are lacking.

In addition, gender and age are considered to be important factors affecting passengers' multitasking activities. Berliner et al. [17] found that male passengers were more likely to use ICT devices (listening to music, watching videos), older travelers were more inclined to activities that did not require ICT devices, such as reading, and younger travelers were more likely to use computers, mobile phones, and so on. However, Lyon et al. [18] found that young travelers were more likely to be bored than middle-aged and elderly travelers. Keseru et al. [19] and Frei et al. [20] found that women were more likely to participate in social activities, such as conversation and reading. Many researchers called for further research on the use of travel time in different countries and different cultural backgrounds [21] because compared with developed countries, there is a lack of research on multitasking in developing countries [10], a deficit in similar research that is necessary to undertake in developing countries.

In the context of sustainable development and electrification revolution in urban transport, this study took Chengdu, a typical city in China (the largest developing country), as an example and selected two electrified intercity railways with an attribute for leisure and commuting. The study obtained the universal evidence and influencing factors of passenger multitasking activities based on the realworld observed data and provided service suggestions related to the passengers' behaviors, railway operation, and policies for relevant government decision-makers to help transition toward urban electrification. This research attempts to answer the following questions:

(1) Does the attribute of the electrified intercity railways (leisure line, commuting line), passenger gender, age, and availability of seats affect passengers' multitasking activities?

(2) Are there any differences in the factors affecting passenger multitasking activities in electrified intercity express rail lines between the attributes leisure and commuting?

The next section of the article introduces the sources and collection methods of passenger multitasking activity data. Section 3 describes the results of the data analysis. Section 4 discusses the results in combination with the previous research and provides some service suggestions. Section 5 summarizes the research results and presents the limitations of this article.

\section{Methods}

2.1. Research Method. In previous studies on passenger multitasking activities, qualitative methods (such as qualitative interviews and focus groups) and quantitative methods (such as questionnaires and observations) have been used. More recently, in this field, structured observation and questionnaire surveys have become the main research methods [10].

This study mainly uses structured observation and instantaneous sampling to collect and record data. Compared with questionnaire surveys, observation has been considered a nonobtrusive method [13] and can be used to collect a large amount of data in a short time to provide researchers with a wealth of information. Under these research conditions, subject behavior tends to be more natural, and researchers can more readily avoid the memory effect inherent to the use of questionnaires [22]. One key issue arising when using the observation method is setting the time of the passenger observation window [23] or how long the passenger's activity frequency and duration are recorded. A longer observation window means a smaller sample size and more observation costs. Gamberini et al. [24] found that $84.2 \%$ of travelers only performed one activity during the observation period, which is consistent with the findings of Van Der Waerden et al. [25]. Therefore, the use of instantaneous sampling - that is, making instantaneous recordings about the activities that passengers are engaged in-is a way to balance cost and efficiency.

2.2. Data Source and Collection. Chengdu is a central city in southwestern China and an important junction and transportation corridor between Southeast Asia and South 
Asia [26]. The geographic locations of the two intercity lines selected are shown in Figure 1, as detailed in the following:

(1) Intercity line from Chengdu to Qingcheng Mountain: the whole journey takes $42 \mathrm{~min}$ and passes through four stops, including famous local attractions. It is presumed to be a leisure line, and the passenger flow is mainly leisure travel, hereinafter referred to as the "leisure line."

(2) Intercity line from Chengdu to Jiangyou: the whole journey takes $1 \mathrm{~h}$ and $13 \mathrm{~min}$ and passes through five stops, which are urban cities around Chengdu (excluding famous tourist cities). It is presumed to be a commuting line. The passenger flow is mainly commuting and business, hereinafter referred to as the "commuting line."

Because of the strong volatility of railway passenger flow, there is a substantial difference in passenger flow between the peak and nonpeak periods. Previous studies have shown that it is almost impossible to conduct an organized observation during peak hours [13, 27]. Hence, most peak hours were not included. However, the method of instantaneous sampling greatly reduces the difficulty and cost of data collection, and since one of our purposes was to study the difference between the two lines, collecting data from peak hours offered the opportunity to make the results more representative. According to previous studies [28], the passenger flow of leisure travel showed its peak during holidays, and the traffic was the largest. The peak of commuter passenger flow occurred between 7:00 and 9:00 and between 17:00 and 19:00 every day. However, commuters taking intercity trains are mostly cross-city, weekly, or monthly commuters. There are few daily commuters [28]. Thus, observations for the commuting line were collected from 16:00 to 19:00 on Friday, December 20, 2019. For the leisure line, the observation was conducted from 9:00 to 12: 00 on Saturday, December 15, 2019. Both investigations were conducted in fair weather without any abnormal conditions.

We began with a preinvestigation of the travel purpose of passengers on the two lines. We randomly distributed questionnaires to passengers on the two lines (103 on the leisure line, 155 on the commuting line). The results of the questionnaire showed the tourist flow of the leisure line to be $67.92 \%$, of which a vast majority of passengers were foreign tourists. The commuter flow of the commuting line was $65.82 \%$, of which most travelers were migrant workers, and the travelers on business accounted for only $7.27 \%$. Both conformed to the original hypothesis of line attribute.

Data collection process: investigator A held a sports camera (GoPro Hero8 Black) in front of his chest and walked from the first carriage to the rear carriage at a normal speed to avoid deliberate data collection for passengers, activities which not only ensured a strong adherence to passenger privacy but also reduced any "observation effect" [29] to obtain the most real data possible.

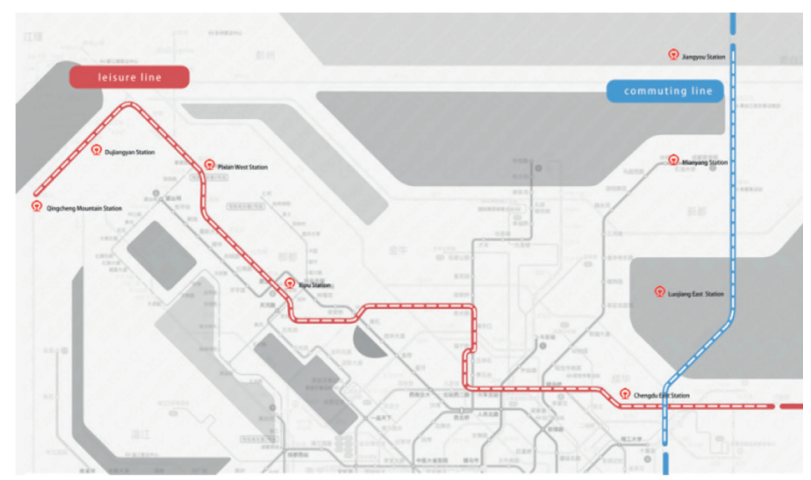

Figure 1: Two electrified intercity lines for data collection.

In recording the data, the researchers conducted preobservations on the collected data and discussed and formulated the observation structure (Table 1), including the specific definitions of variables, such as passenger gender, age, availability of seats, passenger multitasking activities, and standards of invalid filtering information. Two observers were selected from the preobservation to conduct formal observations at the same time to discuss some ambiguous information (such as age) and discard controversial data in a timely manner. On the two lines, a total of 605 passengers were observed (leisure line: 203 times, recording time: $5^{\prime \prime} 56^{\prime}$; commuting line: 405 times, and recording time: $\left.4^{\prime \prime} 18^{\prime}\right)$. Among them, activities that did not meet the specified definitions were not included. As the purpose of passengers walking in the carriage cannot be understood by observation, these observations were discarded. To avoid the impact of seat level differences, the data of the first-class carriage were not included. In addition, a carriage was in a parked state during the observation, and as the observers were strongly interfered with by the passengers getting on and off, these observations were not included in the final dataset. Finally, 507 valid observations were obtained (leisure line: 175 times, commuting line: 332 times). According to previous studies [10], the number of observations is in an intermediate position, which is considered appropriate. The data were strictly kept confidential during the whole process to protect the privacy of passengers.

\section{Results}

Descriptive analysis, single-factor analysis, and multifactor analysis were performed on the observed data. In singlefactor analysis, the chi-square test was performed on multitasking activities and independent variables to initially test the correlation between independent variables and dependent variables, and variables with small correlations would be excluded to make the results more reliable. Then, the binary logistic regression analysis method was used, and odds ratio (OR), which is often used in similar studies $[30,31]$, was selected to test the relationship between the independent variable and activities. 
TABLE 1: A grid for structured observation of passengers on intercity lines.

\begin{tabular}{|c|c|c|}
\hline & $\begin{array}{l}\text { Item } \\
\text { le attribute }\end{array}$ & $\begin{array}{c}\text { Explanatory variable } \\
\text { (Leisure line/commuting line) }\end{array}$ \\
\hline Gender & $\begin{array}{c}\text { Male } \\
\text { Female } \\
\end{array}$ & $\begin{array}{l}\text { Male passengers identified directly through observation } \\
\text { Female passengers identified directly through observation }\end{array}$ \\
\hline Age & $\begin{array}{c}\text { Children } \\
\text { Youth } \\
\text { The middle-aged and elderly }\end{array}$ & $\begin{array}{c}\text { Child passengers aged } 13 \text { or younger perceived through observation } \\
\text { Young passengers aged } 14-39 \text { perceived through observation } \\
\text { Middle-aged and elderly passengers aged } 40 \text { and above perceived through observation }\end{array}$ \\
\hline Availability of seats & $\begin{array}{l}\text { Yes } \\
\text { No }\end{array}$ & $\begin{array}{l}\text { Passengers seated in the seat area of the train } \\
\text { Nonseated passengers standing in the train }\end{array}$ \\
\hline Multitasking activity & Effective activity & $\begin{array}{c}\text { Synchronous multitasking: doing two or more activities at the same time } \\
\text { Being in a daze/looking around } \\
\text { Using the cell phone } \\
\text { Wearing headphones } \\
\text { Talking with other passengers } \\
\text { Resting: resting and sleeping } \\
\text { Talking on the phone } \\
\text { Using computer: using computer or tablet } \\
\text { Reading: reading paper books } \\
\text { Writing: writing using pen and paper } \\
\text { Eating: eating or drinking } \\
\text { Companion care: caring for a child, elderly people, or a companion } \\
\text { Incomplete records or unrecognizable activities }\end{array}$ \\
\hline
\end{tabular}

3.1. Descriptive Statistics. To determine the factors influencing passengers' multitasking activities, the independent variables created were as follows:

(1) Line attribute: use 1 and 2 to represent leisure line and commuting line, respectively

(2) Gender: use 1 and 2 to represent male and female passengers, respectively

(3) Age: use 1 and 2 to denote younger and older passengers, respectively

(4) Availability of seats: use 1 and 2 to indicate seated and nonseated, respectively

Table 2 shows the descriptive statistics. There were slightly more women than men in the sample, which was consistent with the slight imbalance in gender distribution commonly observed among public transport passengers [32]. Through preobservation, children accounted for the smallest proportion, and most of them did not engage in multitasking activities. Hence, the data on children's multitasking were not included. There were fewer middle-aged and elderly travelers. Hence, the two groups were analyzed together. Most of the observed passengers (66.6\%) belonged to the youth group, and the middle-aged and elderly group accounted for a relatively smaller proportion (34.4\%). There were more seated passengers $(77.8 \%)$ than nonseated passengers (22.2\%). The number of activities (581) was more than the number of passengers observed (507), indicating that some passengers performed two or more activities at the same time $(24.6 \%)$.

Figure 2 shows the distribution of passenger activities. Using mobile phones, wearing headphones, being in a daze or looking around, and taking a break were the most popular activities. Talking with other passengers and eating were also distributed but in a small proportion. In contrast, activities, such as companion care, talking on the phone, writing, reading, and using a computer, were rarely distributed.

As passengers had more types of multitasking activities and some activities were less frequent, to better study the links between activities, the activities were further aggregated based on the use of ICT equipment and previous studies $[15,33]$ (Table 3 ). The results were also entered into the regression analysis. Figure 3 shows the overall distribution: ICT-based activities still occupied the main body, and active ICT activities were the most distributed. Figure 4 shows the comparison of the two lines.

3.2. Single Factor Analysis of Passenger Multitasking Activities. We used a four-grid table chi-square test to exclude some variables with a lower degree of fit to ensure a more accurate subsequent multifactor analysis. The standard of significance level in this step was appropriately relaxed: the variable with a $p$-value of 0.15 or less was included in the multifactor analysis. The results of the single factor analysis are shown in Table 4. Line attribute, passenger gender, passenger age, and seat availability had a significant impact on passengers' multitasking activities. Hence, they were all retained, while variables, such as reading, writing, talking, and companion care, showed a small frequency, or the result was not significant. Hence, they were not included in the multifactor analysis.

3.3. Multifactor Analysis of Passenger Multitasking Activities. We used binary logistic regression to conduct a subsequent multifactor analysis, the results of which are shown in Table 5.

On the leisure line, it was easier for passengers to talk with other passengers $(\mathrm{OR}=0.288)$, while on the commuting 
TABLe 2: Descriptive statistics of independent variables.

\begin{tabular}{lccc}
\hline Variable & Value & Number & Proportion (\%) \\
\hline \multirow{2}{*}{ Line attribute } & Leisure line: 1 & 132 & 28.4 \\
& Commuting line: 2 & 332 & 71.6 \\
\multirow{2}{*}{ Gender } & Male: 1 & 230 & 49.6 \\
& Female: 2 & 234 & 50.4 \\
\multirow{2}{*}{ Age } & Youth: 1 & 155 & 66.6 \\
& The middle-aged and elderly: 2 & 361 & 33.4 \\
\multirow{2}{*}{ Availability of seats } & Yes: 1 & 103 & 77.8 \\
\end{tabular}

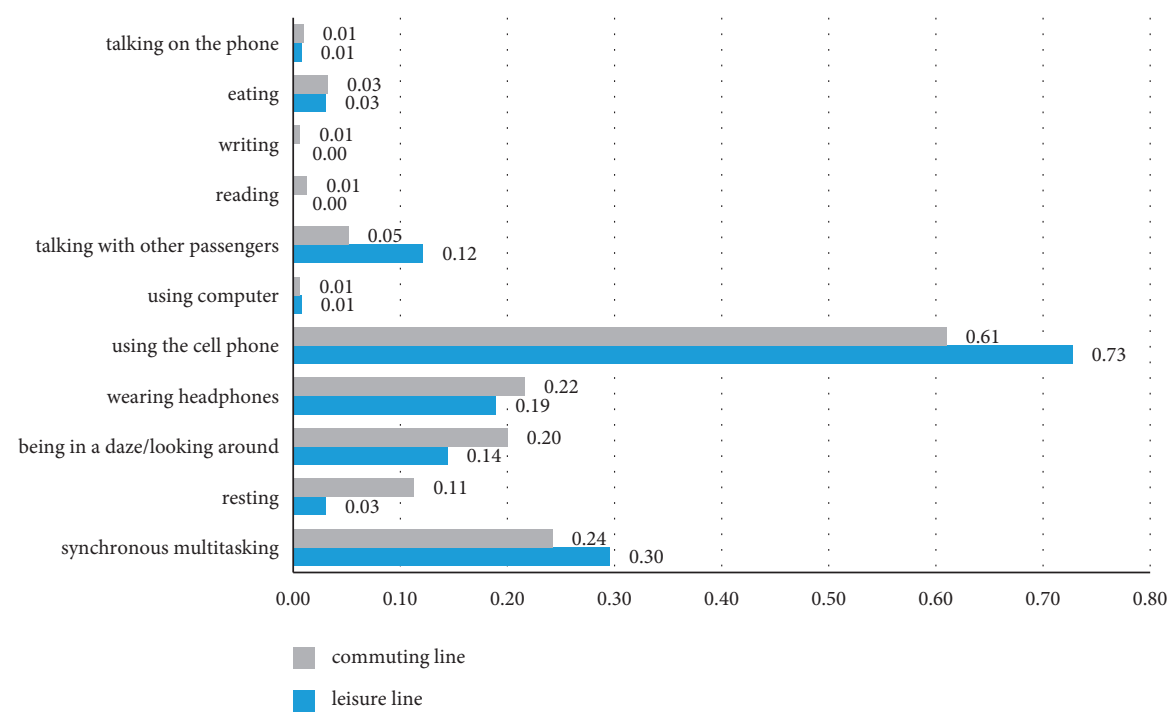

FIGURE 2: The observed distribution of passenger multitasking activities.

TABLE 3: Classification of aggregated multitasking activities.

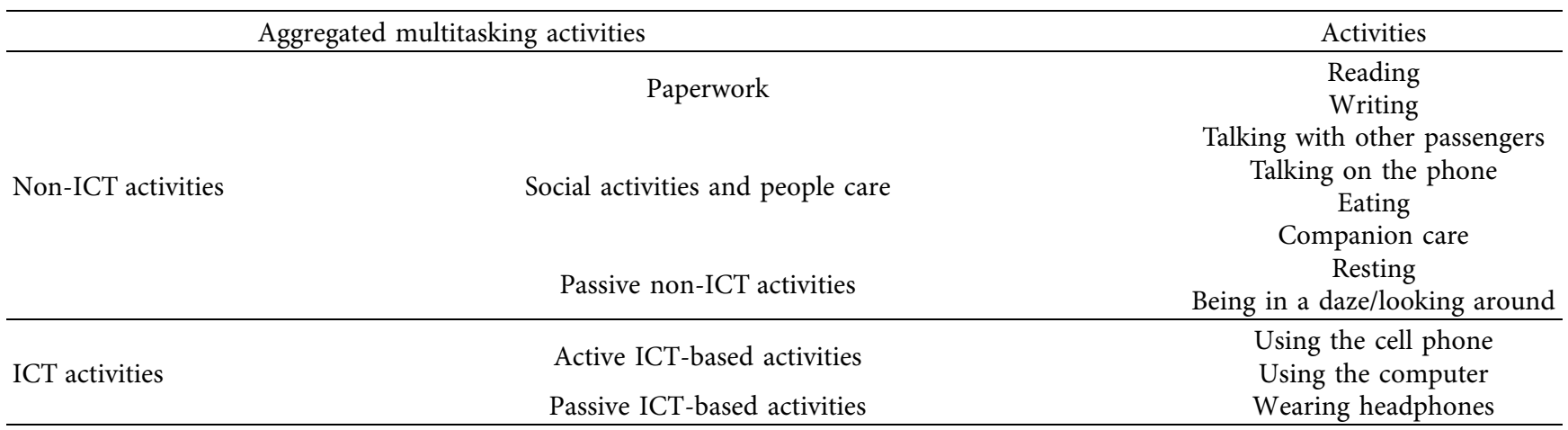

line, it was easier for passengers to sleep and rest $(\mathrm{OR}=3.625)$.

Male passengers were more likely to engage in simultaneous multitasking $(\mathrm{OR}=0.630)$ and wear headphones $(\mathrm{OR}=0.422)$, while female passengers were more likely to engage in resting $(\mathrm{OR}=1.820)$ and eating $(\mathrm{OR}=5.611)$.

Young travelers were more likely to perform simultaneous multitasking $(\mathrm{OR}=0.370)$, wear headsets $(\mathrm{OR}=0.208)$, and use mobile phones $(\mathrm{OR}=0.437)$ than middle-aged and elderly travelers. The middle-aged and elderly travelers were more likely to be in a daze and look around $(\mathrm{OR}=2.705)$.

Seated passengers were more likely to engage in simultaneous multitasking $(\mathrm{OR}=0.462)$, rest $(\mathrm{OR}=0.101)$, and conversations with other passengers $(\mathrm{OR}=0.087)$ than nonseated passengers. Nonseated passengers were more likely to be in a daze and look around $(\mathrm{OR}=1.736)$.

Analyzing the multitasking activities of the two lines separately, the results showed that on the leisure line, men were more likely to engage in simultaneous multitasking 


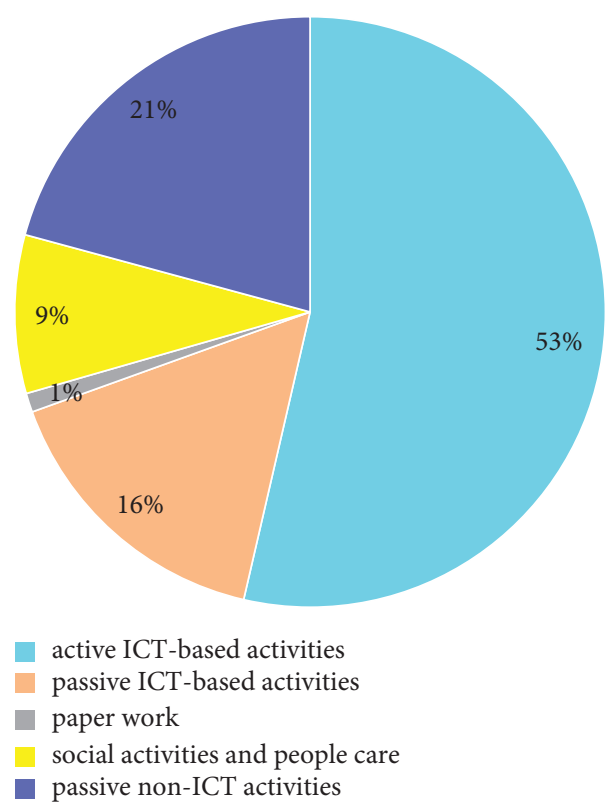

FIgURE 3: Distribution of aggregated multitasking activities.

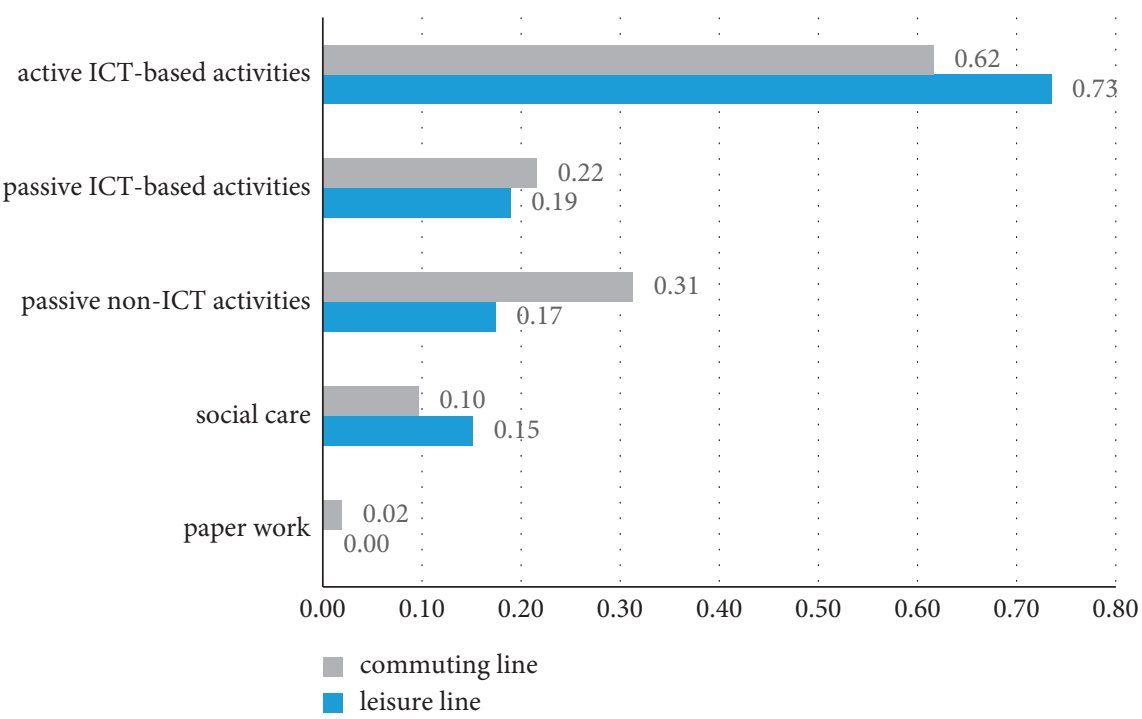

FIgURE 4: Distribution of aggregated multitasking activities on two lines.

$(\mathrm{OR}=0.38)$ while wearing headphones $(\mathrm{OR}=0.26)$, and women were more likely to take breaks $(\mathrm{OR}=1.3)$. Young travelers were more likely to perform multiple activities at the same time $(\mathrm{OR}=0.14)$, wear earphones $(\mathrm{OR}=0.13)$, and use their mobile phones $(\mathrm{OR}=0.18)$, while middle-aged and elderly passengers were more likely to be in a daze/looking around $(\mathrm{OR}=12.12)$. Nonseated passengers were more likely to wear earphones $(\mathrm{OR}=2.27)$.

On the commuting line, men were more likely to wear headphones $(\mathrm{OR}=0.51)$, while women were more likely to eat $(\mathrm{OR}=10.58)$. Young passengers were more likely to carry out multiasking activities at the same time $(\mathrm{OR}=0.45)$, wear headphones $(\mathrm{OR}=0.21)$, and use mobile phones $(\mathrm{OR}=0.55)$, and middle-aged and elderly passengers were more likely to be in a daze, looking around $(\mathrm{OR}=1.74)$ or be and in conversations with others $(\mathrm{OR}=5.1)$. Seated passengers were more likely to carry out multitasking activities at the same time $(\mathrm{OR}=0.37)$ and rest $(\mathrm{OR}=0.1)$, while nonseated passengers were more likely to be in a daze or were more likely to look around $(\mathrm{OR}=1.9)$.

3.4. Multifactor Analysis of Aggregation Multitasking Activities. Next, we performed a binary logistic regression analysis on the aggregate multitasking activities of the passengers, the results from which are shown in Table 6.

Passengers on the leisure line were more likely to engage in social care activities $(\mathrm{OR}=0.5)$, and passengers on the commuting line were more likely to engage in passive nonICT activities $(\mathrm{OR}=1.77)$. Men were more likely to engage in 
TABLE 4: Chi-square test results of multitasking activities.

\begin{tabular}{|c|c|c|c|c|}
\hline \multirow{2}{*}{ Type } & \multicolumn{4}{|c|}{$\chi^{2}$} \\
\hline & Line attribute & Gender & Age & Availability of seats \\
\hline Synchronous multitasking & $2.465^{* *}$ & - & $13.520^{* * *}$ & $3.594^{*}$ \\
\hline Resting & $6.923^{* * *}$ & $3.184^{*}$ & - & $9.504^{* * *}$ \\
\hline Being in a daze/looking around & - & - & $15.010^{* * *}$ & - \\
\hline Wearing headphones & - & $9.733^{* * *}$ & $21.386^{* * *}$ & - \\
\hline Using the cell phone & $4.007^{* *}$ & - & $18.762^{* * *}$ & $2.948^{*}$ \\
\hline Using the computer & - & $3.305^{*}$ & - & - \\
\hline Talking with other passengers & $7.843^{* * *}$ & - & - & $7.240^{* * *}$ \\
\hline Reading & - & - & - & - \\
\hline Writing & - & - & - & - \\
\hline Eating & - & $7.189^{* * *}$ & - & $2.900^{*}$ \\
\hline Talking on the phone & - & - & - & - \\
\hline Companion care & - & - & - & - \\
\hline
\end{tabular}

Note. Only significant models at $10 \%$ level tested using chi-square tests are shown. ${ }^{* * *} p<0.01,{ }^{* *} p<0.05$, and ${ }^{*} p<0.10$

TABLE 5: Logistic regression results of multitasking activities.

\begin{tabular}{|c|c|c|c|c|}
\hline \multirow{2}{*}{$\begin{array}{l}\text { Type } \\
\text { Total }\end{array}$} & \multicolumn{4}{|c|}{ Explanatory variable } \\
\hline & $\begin{array}{l}\text { Line attribute (leisure line: } \\
\text { 1, commuting line: } 2 \text { ) }\end{array}$ & $\begin{array}{l}\text { Gender (male: } \\
\text { 1, female: } 2 \text { ) }\end{array}$ & $\begin{array}{c}\text { Age (youth: } 1 \text {, the middle-aged } \\
\text { and elderly: } 2 \text { ) }\end{array}$ & $\begin{array}{l}\text { Availability of seats } \\
\text { (yes: } 1, \text { no: } 2 \text { ) }\end{array}$ \\
\hline Synchronous multitasking & - & $0.630^{* *}$ & $0.370^{* * *}$ & $0.462^{* *}$ \\
\hline Resting & $3.625^{* *}$ & $1.820^{*}$ & - & $0.101^{* *}$ \\
\hline Being in a daze/looking around & - & - & $2.705^{* * *}$ & $1.736^{*}$ \\
\hline Wearing headphones & - & $0.422^{* * *}$ & $0.208^{* * *}$ & - \\
\hline Using the mobile phone & - & - & $0.437^{* * *}$ & - \\
\hline Computer use & - & - & - & - \\
\hline Talking with other passengers & $0.288^{* * *}$ & - & - & $0.087^{* *}$ \\
\hline Eating & - & $5.611^{* *}$ & - & - \\
\hline \multicolumn{5}{|l|}{ Leisure line } \\
\hline Synchronous multitasking & - & $0.38^{* *}$ & $0.14^{* * *}$ & - \\
\hline Resting & - & $1.3^{*}$ & - & - \\
\hline Being in a daze/looking around & - & - & $12.12^{* * *}$ & - \\
\hline Wearing headphones & - & $0.26^{* * *}$ & $0.13^{*}$ & $2.27^{*}$ \\
\hline Using the mobile phone & - & - & $0.18^{* *}$ & - \\
\hline Computer use & - & - & - & - \\
\hline Talking with other passengers & - & - & - & - \\
\hline Eating & - & - & - & - \\
\hline \multicolumn{5}{|l|}{ Commuting line } \\
\hline Synchronous multitasking & - & & $0.45^{* * *}$ & $0.37^{* *}$ \\
\hline Resting & - & - & - & $0.1^{* *}$ \\
\hline Being in a daze/looking around & - & - & $1.74^{*}$ & $1.9^{* *}$ \\
\hline Wearing headphones & - & $0.51^{* *}$ & $0.21^{* * *}$ & - \\
\hline Using the mobile phone & - & - & $0.55^{* * *}$ & - \\
\hline Computer use & - & - & - & - \\
\hline Talking with other passengers & - & - & $5.10^{* * *}$ & - \\
\hline
\end{tabular}

Note. Only significant models at $10 \%$ level tested using logistic regression are shown. ${ }^{* * *} p<0.01,{ }^{* *} p<0.05$, and ${ }^{*} p<0.10$.

active ICT activities $(\mathrm{OR}=0.66)$ and passive ICT activities $(\mathrm{OR}=0.43)$, while women were more likely to engage in passive non-ICT activities $(\mathrm{OR}=1.55)$. Young passengers were more likely to engage in active ICT activities $(\mathrm{OR}=0.4)$ and passive ICT activities ( $\mathrm{OR}=0.22$ ), and middle-aged and elderly travelers were more likely to engage in passive nonICT activities $(\mathrm{OR}=2.25)$. Passengers with seats were more likely to engage in social care activities $(\mathrm{OR}=0.25)$.

Analyzing the two lines separately, the results showed that on the leisure line, male passengers $(\mathrm{OR}=0.26)$, young passengers $(\mathrm{OR}=0.13)$, and nonseated passengers $(\mathrm{OR}=2.27)$ were more likely to engage in passive ICT activities, and young passengers were more likely to engage in active ICT activities $(\mathrm{OR}=0.17)$, while middle-aged and elderly passengers were more likely to engage in passive nonICT activities $(O R=9.6)$, and seated passengers were more likely to engage in social care activities $(\mathrm{OR}=0.11)$.

On the commuting line, male passengers were more likely to engage in active ICT activities $(\mathrm{OR}=0.65)$ and passive ICT activities $(\mathrm{OR}=0.51)$, while female passengers 
TABLE 6: Summary of logistic regression results for aggregated multitasking activity types.

\begin{tabular}{|c|c|c|c|c|}
\hline \multirow{2}{*}{$\begin{array}{l}\text { Aggregated multitasking } \\
\text { activity types } \\
\text { Total }\end{array}$} & \multicolumn{4}{|c|}{ Explanatory variable } \\
\hline & $\begin{array}{l}\text { Line attribute (leisure line: } 1 \text {, } \\
\text { commuting line: } 2 \text { ) }\end{array}$ & $\begin{array}{l}\text { Gender (male: } 1 \text {, } \\
\text { female: } 2 \text { ) }\end{array}$ & $\begin{array}{l}\text { Age (youth: } 1 \text {, the middle- } \\
\text { aged and elderly: } 2 \text { ) }\end{array}$ & $\begin{array}{l}\text { Availability of seats } \\
\text { (yes: } 1 \text {, no: } 2 \text { ) }\end{array}$ \\
\hline Non-ICT activities & - & $1.52^{* *}$ & $2.33^{* * *}$ & - \\
\hline Paperwork & - & - & - & - \\
\hline $\begin{array}{l}\text { Social activities and people } \\
\text { care }\end{array}$ & $0.50^{* *}$ & - & - & $0.25^{* * *}$ \\
\hline Passive non-ICT activities & $1.77^{* *}$ & $1.55^{* *}$ & $2.25^{* * *}$ & - \\
\hline ICT activities & - & $0.62^{* * *}$ & $0.35^{* * *}$ & - \\
\hline Active ICT-based activities & - & $0.66^{* *}$ & $0.40^{* * *}$ & - \\
\hline $\begin{array}{l}\text { Passive ICT-based } \\
\text { activities }\end{array}$ & - & $0.43^{* * *}$ & $0.22^{* * *}$ & - \\
\hline \multicolumn{5}{|l|}{ Leisure line } \\
\hline Non-ICT activities & - & - & $3.20^{* * *}$ & $0.31^{* *}$ \\
\hline Paper work & - & - & - & \\
\hline $\begin{array}{l}\text { Social activities and people } \\
\text { care }\end{array}$ & - & - & - & $0.11^{* *}$ \\
\hline Passive non-ICT activities & - & - & $9.6^{* * *}$ & - \\
\hline ICT activities & - & $0.40^{* *}$ & $0.14^{* * *}$ & - \\
\hline Active ICT-based activities & - & & $0.17^{* * *}$ & - \\
\hline $\begin{array}{l}\text { Passive ICT-based } \\
\text { activities }\end{array}$ & - & $0.26^{* * *}$ & $0.13^{* *}$ & $2.27^{*}$ \\
\hline \multicolumn{5}{|l|}{ Commuting line } \\
\hline Non-ICT activities & - & $1.55^{* *}$ & $2.02^{* * *}$ & - \\
\hline Paperwork & - & - & - & - \\
\hline $\begin{array}{l}\text { Social activities and people } \\
\text { care }\end{array}$ & - & - & $3.02^{* * *}$ & - \\
\hline Passive non-ICT activities & - & $1.54^{*}$ & $1.58^{*}$ & - \\
\hline ICT activities & - & $0.66^{*}$ & $0.47^{* * *}$ & - \\
\hline Active ICT-based activities & - & $0.65^{*}$ & $0.55^{* * *}$ & - \\
\hline $\begin{array}{l}\text { Passive ICT-based } \\
\text { activities }\end{array}$ & - & $0.51^{* *}$ & $0.21^{* * *}$ & $0.31^{* * *}$ \\
\hline
\end{tabular}

Note. Only significant models at $10 \%$ level tested using logistic regression are shown. ${ }^{* * *} p<0.01,{ }^{* *} p<0.05$, and ${ }^{*} p<0.10$.

were more likely to engage in passive non-ICT activities $(\mathrm{OR}=1.54)$. Young passengers were more likely to engage in active ICT activities $(\mathrm{OR}=0.55)$ and passive ICT activities $(\mathrm{OR}=0.21)$, while middle-aged and elderly passengers were more likely to engage in social care activities $(\mathrm{OR}=3.02)$ and passive non-ICT activities $(\mathrm{OR}=1.58)$. Seated passengers appeared to find it easier to engage in social care activities $(\mathrm{OR}=0.31)$.

\section{Discussion}

\subsection{Factors Affecting Passenger Multitasking Activities on Electrified Intercity Railways}

4.1.1. The Impact of Line Attribute on Passenger Multitasking Activities. The results of binary logistic regression analysis show that passengers on the leisure line were more likely to engage in social care activities (talking and eating), and passengers on the commuting line were more likely to engage in passive non-ICT activities (rest). The reason may be that passengers on the leisure line take leisure as the main purpose, and they tend to eat and chat with their companions. Passengers on the commuting line mainly commute to work, and passive activities, such as rest and daze, are beneficial to their preservation and recovery.

In recent years, only a few studies have compared the two different lines. However, similar studies focused on the analysis of the travel purpose of passengers. For example, Lyons et al. [18] found that commuters were more likely to engage in relaxation, leisure, and social activities, such as reading, listening to music, or making a phone call. Business travelers preferred to work, call, send text messages, and check e-mails, while leisure travelers preferred to relax and talk with others. We have found similar results in this article.

4.1.2. The Impact of Gender, Age, and Availability of Seats on Passenger Multitasking Activities. As our results show, male travelers were more likely to perform simultaneous multitasking, active ICT activities, and passive ICT activities, the results of which are consistent with previous studies $[17,24,34]$. Female passengers were more likely to engage in passive non-ICT activities, such as resting and eating. Hence, power bank rental and sales services may be provided on the train, along with low-fat and low-sugar snacks and beverages, which are more likely to be preferred by women. 
Age also had a strong influence on the types of multitasking activities. Compared with middle-aged and elderly travelers, young travelers were more likely to engage in active ICT activities (using mobile phones) and passive ICT activities (wearing headphones), and middle-aged and elderly travelers were more likely to be in a daze, look around, or engage in other passive non-ICT activities during their journeys. Interestingly, there was no difference in the resting activities between young and old travelers, indicating that compared with younger travelers, middle-aged and elderly travelers were not more likely to feel tired and need to rest during the trip, which differs from our initial assumptions. It indicates that middle-aged and elderly travelers have the energy to carry out activities during the journey, however, compared to ICT activities that require more energy, they may be more comfortable engaging in passive activities. Therefore, more passive non-ICT services could be provided for elderly passengers, such as magazines or interesting carriage interior design. For example, the interior design of trains on the leisure line can be derived from the local history and culture. Although young travelers tended to engage in ICT activities during their travels, Lyon et al. [18] found that they were easily bored, indicating that they may not really want to engage in ICT activities during the trip. ICT activities may just represent a limited choice under restricted conditions and can be further studied through questionnaires in the future.

We also compared the difference between seated and nonseated passengers. Many passengers buy station tickets for short journeys when seats are sold out. The results of our study show that the seated passengers were more likely to engage in social care activities, such as simultaneous multitasking, resting, and talking, than passengers without seats. There is also a certain logic to this phenomenon: generally speaking, when sitting on a train, it is easier to carry out many of these activities than while standing, which is consistent with the content reported by Zhang et al. [35].

\subsection{Differences in the Factors Affecting Multitasking Activities in the Two Lines}

4.2.1. Multitasking Activities on the Leisure Line. On the leisure line, male passengers were more likely to engage in passive ICT activities (wear headphones), while women were more likely to take breaks and rest, indicating that male passengers may prefer immersive ICT experiences or pursue a personal immersive activity, such as playing a game or watching videos while wearing headphones. One reason may be that travel, as a process of moving from the departure place to the destination, provides an illusion of transition between different realities. In this transition time, male travelers may be more inclined to immerse themselves in their personal world and enjoy the leisurely time for themselves. This finding is similar to the concept of "me time" proposed by Jain et al. [36]. Women may also need this immersive experience, however, compared to men, female travelers may be less likely to use ICT devices. Hence, the results suggested that they were more inclined to rest.
As our results suggest, young travelers preferred ICT activities (using mobile phones and wearing headphones) on the leisure line, while middle-aged and elderly travelers preferred passive non-ICT activities (dazing or looking around), and the difference was extremely significant $(P<0.01)$. It shows that middle-aged and elderly passengers have a significant preference for dazing and looking around on the leisure line, and no preference for resting could be determined.

Compared with nonseated passengers, seated passengers were found to be more likely to engage in social care activities on the leisure line, such as talking or eating, while nonseated passengers preferred to wear headphones. Passengers with seats indicated that they were more willing to engage in social activities, while passengers without seats preferred passive personal immersive activities, such as listening to music.

4.2.2. Multitasking Activities on the Commuting Line. On the commuting line, male passengers were more likely to engage in ICT activities, and female passengers were more likely to engage in passive non-ICT activities (eating). Female passengers may be more likely to prepare or buy food on commuter trains. Hence, providing food sales services that are preferred by women is a service addition worth considering. Middle-aged and elderly travelers also preferred to talk to other travelers, daze, or look around, showing that they may prefer non-ICT activities that consume less energy. Compared to nonseated travelers, seated travelers found it easier to carry out social care activities, which is also consistent with the results of the leisure line.

4.3. Service Suggestions on Different Lines. Based on the differences between commuting and leisure lines and their respective characteristics, service suggestions for relevant government decision-makers are provided below to help improve the attraction and use of intercity railways and to further transition toward urban electrification.

4.3.1. On the Leisure Line. Considering that passengers on the leisure line prefer social and leisure activities, it may be possible to provide passengers with automatic vending services and optimize the seat layout to facilitate passengers' social activities. Men and young travelers on this line were more likely to perform multiple activities at the same time and ICT activities (wear earphones, use mobile phones), indicating that they need a power supply or mobile power, which are currently not provided on this line according to our observations. Therefore, power bank rental services targeted to male and young travelers could be considered.

In addition, middle-aged and elderly passengers on this line were found to prefer to be in a daze, and therefore, more passive non-ICT services for middle-aged and elderly groups could be considered, such as providing in-car reading materials or interior design related to local culture.

As the results suggest, seated passengers were more likely to engage in social care activities on the leisure line. 
Therefore, the layout of train seats could be optimized for the social needs of passengers, and for passengers without seats, more personal immersive regional services could be provided for their participation, such as the provision of online descriptions of local attractions.

4.3.2. On the Commuting Line. Generally speaking, compared with the leisure line, the commuter line has a more obvious bias toward rest. Hence, it is possible to consider providing rest-related services on this line. For example, Lyons et al. [21] suggested that listening to music could make the journey more enjoyable for passengers. It also helps commuters overcome the pressure of being close to others by creating a psychological distance. Music and lights could be provided on the commuting line, for example, to create a quiet and comfortable environment for passengers. Earplugs, eye masks, and other goods that help people rest could also be provided in the carriage. In addition, to prevent passengers from sleeping past their station, getting off reminders can also be considered.

The same results were found on the leisure line for men and young travelers, who were more likely to perform multiple activities at the same time along with ICT activities (wear earphones, use mobile phones). Therefore, power bank rental services could be considered. Low-fat and lowsugar snacks and beverages that are more likely preferred by women can also be considered because female passengers were more inclined to eat in the commuting line, as observed from the results.

\section{Conclusion}

This study introduces passenger multitasking activities and influencing factors on electrified intercity railways. It focused on a comparative analysis of the two lines and found that there were differences in the types of passenger activities between the leisure and the commuting line. On the leisure line, passengers preferred to engage in social activities, such as talking with others, and middle-aged and elderly passengers on this route were often found to be doing nothing in the carriage (in a daze or looking around). Passengers on the commuting line, by contrast, were found to prefer rest, and nonseated passengers on this line tended to be idle. We also found that demographic characteristics (age, gender) and availability of seats also affected passenger activities. Male travelers and young travelers were more likely to engage in ICT-related immersive activities (using mobile phones and wearing headphones), while women, middle-aged, and elderly travelers tended to engage in non-ICT immersive activities. Women preferred to rest, while middle-aged and elderly passengers preferred to stay in a daze and look around. Seated passengers were found to be more likely to engage in activities, such as simultaneous multitasking, resting, and talking than the nonseated passengers. The conclusion can be used for reference by relevant departments to improve services and attract more passengers to take electrified intercity lines. However, there are some limitations to this study. Firstly, it is difficult to cover all the time periods of the day. The data during peak periods alone were collected.
Secondly, since the main method used was a structural observation, the number of useful variables collected was relatively small. In the future, more information on travel attributes and ride experience of passengers can be collected through questionnaires, and the number of variables can be increased to make the model more accurate.

\section{Data Availability}

No additional data were used to support this study.

\section{Additional Points}

Highlights. The line attributes of the electrified intercity rail line, passenger gender, age, and availability of seats have a significant impact on passenger multitasking activities. On the leisure line, passengers preferred social activities, while middle-aged and elderly passengers preferred to engage in passive non-ICT activities, such as staring in a daze, and no obvious preference for resting was found with them. On the commuting line, passengers preferred to rest, and passengers without seats tended to do nothing. Male travelers and young travelers preferred ICT immersive activities, while women, middle-aged, and elderly travelers were more likely to engage in non-ICT immersive activities. Passengers with seats were more likely to engage in simultaneous multitasking activities, rest, and conversation than nonseated passengers.

\section{Conflicts of Interest}

The authors declare that they have no conflicts of interest.

\section{Authors' Contributions}

The authors Xing Yao and Chunhui Jing contributed equally to this work.

\section{Acknowledgments}

This work was supported by the National Natural Science Foundation of China (grant no. 52175253); MOE Layout Foundation of Humanities and Social Sciences (grant no. 19YJA760094); General Project of Sichuan Multicultural Research Center (grant no. DYWH2122); Sichuan Key Research Base of Philosophy and Social Sciences-National Park Research Center (grant no. GJGY2021-YB006); General Project of Sichuan Applied Psychology Research Center (grant no. CSXL-212A03); and Practice Base Project in the Graduate School of Southwest Jiaotong University. The authors thank LetPub (http://www.letpub.com) for its linguistic assistance during the preparation of this manuscript.

\section{References}

[1] Y. Bousse, M. V. Corazza, G. Sessing, D. S. Arriaga, and D. Salzillo, "Electrification of public transport in Europe: vision and Practice from the ELIPTIC project," in Proceedings of the 2018 IEEE International Conference on Environment and Electrical Engineering and 2018 IEEE Industrial and Commercial Power Systems Europe (EEEIC/I\&CPS Europe), June, 2018. 
[2] M. Glotz-Richter and H. Koch, "Electrification of public transport in cities (horizon 2020 ELIPTIC project)," Transportation Research Procedia, vol. 14, pp. 2614-2619, 2016.

[3] L. Moretti and G. Loprencipe, "Climate change and transport infrastructures: state of the art," Sustainability, vol. 10, no. 11, p. 4098, 2018.

[4] L. Yang, J. Zhou, O. F. Shyr, and D. Huo, "Does bus accessibility affect property prices?” Cities, vol. 84, pp. 56-65, 2019.

[5] L. Yang, X. Chu, Z. Gou, H. Yang, Y. Lu, and W. Huang, "Accessibility and proximity effects of bus rapid transit on housing prices: heterogeneity across price quantiles and space," Journal of Transport Geography, vol. 88, Article ID 102850, 2020.

[6] L. Yang, K. W. Chau, W. Y. Szeto, X. Cui, and X. Wang, "Accessibility to transit, by transit, and property prices: spatially varying relationships," Transportation Research Part D: Transport and Environment, vol. 85, Article ID 102387, 2020.

[7] W. Xu, J. Zhou, L. Yang, and L. Li, "The implications of highspeed rail for Chinese cities: connectivity and accessibility," Transportation Research Part A: Policy and Practice, vol. 116, pp. 308-326, 2018.

[8] R. G. Mugion, M. Toni, H. Raharjo, L. Di Pietro, and S. P. Sebathu, "Does the service quality of urban public transport enhance sustainable mobility?" Journal of Cleaner Production, vol. 174, pp. 1566-1587, 2018.

[9] J. Zhou, L. Yang, J. Liu, and C. Zhang, "Beating long trips with a smartphone? A case study of Beijing residents," Cities, vol. 73, pp. 36-43, 2018.

[10] I. Keseru and C. Macharis, "Travel-based multitasking: review of the empirical evidence," Transport Reviews, vol. 38, no. 2, pp. 162-183, 2018.

[11] G. Circella, P. L. Mokhtarian, and L. K. Poff, "A conceptual typology of multitasking behavior and polychronicity preferences," Electronic International Journal of Time Use Research, vol. 9, no. 1, pp. 59-107, 2012.

[12] G. Lyons and J. Urry, "Travel time use in the information age," Transportation Research Part A: Policy and Practice, vol. 39, no. 2-3, pp. 257-276, 2005.

[13] M. L. Russell, "Watching passengers: using structured observation methods on public transport," in Proceedings of the 43rd Universities Transport Study Group Conference, Milton Keynes, UK, January 2011.

[14] P. A. Singleton, "Multimodal travel-based multitasking during the commute: who does what?" International Journal of Sustainable Transportation, vol. 14, no. 2, pp. 150-162, 2019.

[15] I. Keseru, E. Heyndels, T. Dat Ton, and C. Macharis, "Multitasking on the go: an observation study on local public transport in Brussels," Travel Behaviour and Society, vol. 18, pp. 106-116, 2020.

[16] K. Utsunomiya, "The impact of regional railways on travel behaviour and social capital," Research in Transportation Economics, vol. 83, Article ID 100945, 2020.

[17] R. M. Berliner, A. Malokin, G. Circella, and P. L. Mokhtarian, "Travel-based multitasking: modeling the propensity to conduct activities while commuting," in Proceedings of the Transportation Research Board 94th Annual Meeting, Washington, DC, USA, January 2015.

[18] G. Lyons, J. Jain, and I. Weir, "Changing times - a decade of empirical insight into the experience of rail passengers in Great Britain," Journal of Transport Geography, vol. 57, pp. 94-104, 2016.

[19] I. Keseru, J. Bulckaen, C. Macharis, J. Minnen, I. Glorieux, and T. P. Van Tienhoven, "Is travel time wasted? Evidence from a time use survey in Flanders, Belgium," in Proceedings of the 14th International conference on travel behaviour research, IATBR, Windsor, UK, July 2015.

[20] C. Frei, H. S. Mahmassani, and A. Frei, "Making time count: traveler activity engagement on urban transit," Transportation Research Part A: Policy and Practice, vol. 76, pp. 58-70, 2015.

[21] G. Lyons, J. Jain, Y. Susilo, and S. Atkins, "Comparing rail passengers' travel time use in great britain between 2004 and 2010," Mobilities, vol. 8, no. 4, pp. 560-579, 2013.

[22] H. Timmermans and P. Van der Waerden, "Synchronicity of activity engagement and travel in time and space," Transportation Research Record: Journal of the Transportation Research Board, vol. 2054, no. 1, pp. 1-9, 2008.

[23] S. Sudman and N. M. Bradburn, "Effects of time and memory factors on response in surveys," Journal of the American Statistical Association, vol. 68, no. 344, pp. 805-815, 1973.

[24] L. Gamberini, A. Spagnolli, A. Miotto, E. Ferrari, N. Corradi, and S. Furlan, "Passengers' activities during short trips on the London Underground," Transportation, vol. 40, no. 2, pp. 251-268, 2013.

[25] P. Van Der Waerden, H. Timmermans, and R. Van Neerven, "Extent, nature, and covariates of multitasking of rail passengers in an urban corridor," Transportation Research Record: Journal of the Transportation Research Board, vol. 2110, no. 1, pp. 106-111, 2009.

[26] A. Schneider, K. C. Seto, and D. R. Webster, "Urban growth in Chengdu, Western China: application of remote sensing to assess planning and policy outcomes," Environment and Planning B: Planning and Design, vol. 32, no. 3, pp. 323-345, 2005.

[27] N. Ohmori and N. Harata, "How different are activities while commuting by train? A case in tokyo," Tijdschrift voor Economische en Sociale Geografie, vol. 99, no. 5, pp. 547-561, 2008.

[28] K. Wu, C. Fang, M. Zhao, and C. Chen, "The intercity space of flow influenced by high-speed rail: a case study for the rail transit passenger behavior between Beijing and Tianjin," Acta Geographica Sinica, vol. 68, no. 2, pp. 159-174, 2013.

[29] A. Willis, N. Gjersoe, C. Havard, J. Kerridge, and R. Kukla, "Human movement behaviour in urban spaces: implications for the design and modelling of effective pedestrian environments," Environment and Planning B: Planning and Design, vol. 31, no. 6, pp. 805-828, 2004.

[30] R. C. P. Wong, W. Y. Szeto, L. Yang, Y. C. Li, and S. C. Wong, "Public transport policy measures for improving elderly mobility," Transport Policy, vol. 63, pp. 73-79, 2018.

[31] L. Yang, Y. Ao, J. Ke, Y. Lu, and Y. Liang, "To walk or not to walk? Examining non-linear effects of streetscape greenery on walking propensity of older adults," Journal of Transport Geography, vol. 94, Article ID 103099, 2021.

[32] E. Cornelis, M. Hubert, and P. Huynen, "Belgian Daily Mobility-BELDAM: Enquete sur la mobilite quotidienne des belges: rapport final," Politique Scientifique federale, Brussels, Belgium, 2012.

[33] J. Tang, F. Zhen, J. Cao, and P. L. Mokhtarian, "How do passengers use travel time? A case study of Shanghai-Nanjing high speed rail," Transportation, vol. 45, no. 2, pp. 451-477, 2018.

[34] T. Bjørner, "Time use on trains: media use/non-use and complex shifts in activities," Mobilities, vol. 11, no. 5, pp. 681-702, 2016.

[35] J. Zhang and H. Timmermans, "Scobit-based panel analysis of multitasking behavior of public transport users," Transportation Research Record: Journal of the Transportation Research Board, vol. 2157, no. 1, pp. 46-53, 2010.

[36] J. Jain and G. Lyons, "The gift of travel time," Journal of Transport Geography, vol. 16, no. 2, pp. 81-89, 2008. 